\title{
From Danger to Uncertainty: Changing Health Care Practices, Everyday Experiences, and Temporalities in Dealing With COVID-19 Policies in the Netherlands
}

\author{
Christian Bröer'D, Gerlieke Veltkamp', Carolien Bouw', \\ Noa Vlaar', Femke Borst', and Rein de Sauvage Nolting'
}

\begin{abstract}
Based on ongoing longitudinal research in families with young children, we investigate parents' changing everyday experiences and health care practices of dealing with COVID-19 policies in the Netherlands from March to June 2020. We identify four key themes developing over time. In relation to evolving COVID-19 prevention policies, (a) the lockdown interrupted life and experiences of temporality. (b) Following the lockdown, risk management changed from fear to insecurities and (c) simultaneously, emotion management transitioned from solidarity to fragmentation. (d) Increasingly, pragmatic considerations allowed parents to tackle uncertainties and created room to normalize everyday life. We studied "change" by using a novel conceptual model for temporality and found distinct temporalities in parents' accounts. In sum, we interpret this as a shift from danger to uncertainty, induced by policy shifts and pragmatically translating those to the lifeworld.
\end{abstract}

\section{Keywords}

longitudinal ethnography; COVID-I9 policies; parenting; risk; emotion work; temporality; qualitative; the Netherlands

\section{Introduction}

In times of crisis or natural hazards (Beck et al., 1994; Giddens, 1991), such as the virus SARS-CoV-2 spreading all over the globe, many people have little experiential knowledge or routines to rely on when dealing with the new and changed situation. These types of events therefore create uncertainty and make it difficult for individuals to know how to behave, how to manage emotions, and what to expect in the present and near or distant future. Most of our knowledge comes from others, from public debate, from professionals and scientists, and - notably in this case-from public health policy interventions. Such macro-level COVID-19 prevention policies fundamentally impact on individual lives on the micro-level.

Governments, also dealing with a new situation, seek ways to control the virus, and struggle to weigh "sideeffects" of control measures and vie to project legitimate aims of controlling. In this search for appropriate regulations, broad cultural differences can be found between countries or even regions in handling COVID-19 (Brown,
2020). We examine in this article how households in the Netherlands are dealing with the threat of the virus and with evolving government policies to understand how these household practices (Blue et al., 2016) vary and change over time.

We explore the ongoing changes in mundane health care (see also Kamin et al., 2020) on the basis of an ongoing and long-running ethnographic panel study of parents with young children. Families with young children can be characterized as being in a significant and potentially "fateful" (Giddens, 1991) phase of their lives. Partners turn into parents and enter uncharted territory with a vulnerable and dependent infant, while they are often dealing with career development, asset building, and finding a work-life balance (Grunow \& Veltkamp,

\footnotetext{
'University of Amsterdam, Amsterdam, The Netherlands
}

\section{Corresponding Author:}

Christian Bröer, Department of Sociology, University of Amsterdam, 1000 GG Amsterdam, The Netherlands.

Email: c.broer@uva.nl 
2016). Moreover, an "intensive parenting ideology" (Hays, 1996), underpinned by scientific research suggests that parents and, in particular, mothers are seen as children's "risk managers" and an extension of public health objectives (Knaak, 2010; Lee et al., 2010). This parenting ideal places high expectations and pressures on mothers to care for their children's physical, emotional, and psychological health (Faircloth, 2014).

Chasson and Taubman-Ben-Ari (2020) have pointed to the effects of primary care on the mental states of mothers and on the mental toll of caring for an infant. Mothers deal with difficulties, pleasure and satisfaction, and concern for personal needs, which can be seen as forms of compassion (including fatigue, satisfaction, and self-compassion). In light of this, Veltkamp et al. (2020) emphasize the at times contradicting labor market and care demands on mothers and fathers, typical of late-modern welfare states in which family practices develop. We might therefore expect parents, and especially mothers, of young children to be particularly sensitive to both COVID-19 health risks and mitigation measures. By conceptualizing COVID-19 as a "risk," we can study how public health policy brings the future to the present, imbues probability with emotion and meaning, and establishes selective countermeasures (Brown, 2020). Moreover, as Brown and de Graaf (2013, p. 543) state, "Time considerations are fundamental to risk, with conceptions of time located in the future intrinsic to experiences of uncertainty and considerations of the self." Therefore, we examine in this article how families in turn construct risks and manage their emotions within the particular evolving policy context, and how this relates to their experiences of temporality.

The risk perspective also entails that it is not the epidemic itself directly challenging people or society-as some early claims have it (see, for example, Matthewman \& Huppatz, 2020) - but rather the entanglement of the virus and the response. As we have seen, for example, in the case of SARS in 2009, even the fear of an epidemic which did not arrive can have profound effects on people's lives (Jiang, 2009).

Speaking of "families with young children," it is evident that roles and tasks are gendered and intersect with other inequalities. In dealing with home isolation, scholars have restated that women bear the brunt of home cooking and care tasks already (Swan, 2020) and that even in situations or relative gender parity, the lockdown forced women into more traditional gender roles at home (Hjálmsdóttir \& Bjarnadóttir, 2020). While there is growing evidence of this unequal distribution (see for a relative stronger decline of well-being among mothers during lockdown: Möhring et al., 2021), research also suggests that home isolation can strengthen bonds and be valued by mothers (eg. Evans et al., 2020).
For the purposes of this research, we have had regular contact with 17 families that were already participating in our ethnographic panel since the end of March 2020. This has enabled us to apply a dynamic perspective and systematically describe and contextualize the changes that occur as the families cope with the restrictions and threats brought by COVID-19. We specifically address the political context in which practices emerge rather than other social contexts, such as the economic position of a household. The ways in which parents and children deal with COVID-19 can have long-term consequences when daily practices such as eating or exercising change permanently. We will therefore remain in touch with the families and also try to uncover how COVID-19 shapes or changes their lives in the longer term. In this article, however, we interpret pragmatic changes in the period from March to June 2020 in relation to changing COVID-19 social distancing and home isolation policies. Methodologically, we propose a set of sensitizing concepts as a means of understanding the modes of temporality in changes to everyday life.

\section{Background}

From the perspective of a largely macro-oriented sociology of risk (Beck et al., 1994; Brown, 2020; Giddens, 1991; Lupton, 2006), one can argue that COVID-19 derives its relevance and meaning from cultural values, the exercise of political power and structural shifts in modernity, for example, toward increasing uncertainty and reflexivity. Shifting the focus to the lifeworld, authors such as Zinn (2008) have argued that in dealing with the more unsettling aspects of risk (Alaszewski \& Coxon, 2009), people continuously mingle emotion, (dis)trust, intuition, norms, and pragmatic considerations. Following the study of Cohen (1995) on the way parents deal with the uncertainties in treatments of their sick children, Parry (2003) argues that uncertainties too narrowly have been approached as a threat triggering coping. Her research among former cancer patients suggests that uncertainties can be an opportunity for "growth" (see also Miao et al., 2020).

Conceptualizing COVID-19 as a risk unfolding between structural changes and lifeworld concerns also implies that notions of time and temporality are affected, and that probabilities come to be related to emotions and meanings (Brown, 2020). We disentangle such "emotionrisk assemblages" in everyday life (Lupton, 2013) in this article using the concept of emotion work as developed by Hochschild (1979).

Hochschild (1979, p. 566) asserts that people manage their emotions to fit the "feeling rules" and "framing rules" that govern specific situations. Feeling rules are "guidelines for the assessment of fits and misfits between 
feeling and situation" while framing rules are "the rules according to which we ascribe definitions or meanings to situations." We thus investigate in this article whether and how changing "feeling and framing rules" in COVID19 policies are relevant in household practices and which different constructions of risk, uncertainty, and temporality are implied.

We interpret the changes in health risk practices and emotion management within households from the perspective of the potentially subject-forming mechanisms of policy (Bröer, 2006; de Graaff \& Bröer, 2019). This means that we assume that health policy literally implements a specific construction of a risk (Hajer, 2003) and that citizens react to this construction of meaning and its feeling rules (Hochschild, 1979).

Moreover, we show how the construction of risk changes over time and implies different modes of temporality. Looking at qualitative longitudinal studies on health, Ramanujam et al. (2020) found that many studies did not address change and instead performed a merely static analysis. Other studies, mostly implicitly, were modeled in a specific temporality. Neale (2015) suggests, however, that "time" in a qualitative longitudinal study offers a conceptual utility as well as a methodological strategy, which allows us to challenge time as merely a linear progression (Felt et al., 2014) and show instead how people's lives unfold through a variety of temporal frames. Accordingly, we propose a distinction between five types of temporality in changes over time: interruptions, continuous change, phasic change, cyclical changes (derived from Ramanujam et al., 2020), and we have added a fifth mode: uncertainty. These modes of temporality are relevant to how researchers deal with changes they find through longitudinal research and can likewise be used to study research subjects' perceptions. Adding an analytical category of "uncertainty" enables us to denote changes which are inherently ambiguous or multi-interpretable in relation to the wider social context and does justice to interpretive work in which we often encounter observations about change of unclear status. Our model invites researchers to see whether indeterminacy of changes can be resolved by prolonging the analysis or by adding the category of uncertainty as a second-order concept of temporality. Moreover, as Emirbayer and Mische (1998) suggest, the ability — or inability - to focus on projective elements of the future is informed by the temporalrelational context. We pay attention to these forms of temporality during the analysis. The five modes of temporality are:

Interrupted Time: First, the fairly speedy arrival of COVID-19 and sudden isolation may have brought about a break in everyday life, known as a "biographical disruption" (Bury, 1982). The taken-for-granted experience of the progress of time is interrupted, heralding a new experiential reality.

Continuous Time: Second, we can conceptualize changes as continuous and gradual increases or decreases in a clearly defined and otherwise stable variable. This is common in psychometric research and in much survey research in general.

Phasic Time: Third, conceptualizing temporality in change is a phase model. Here, attention is paid to qualitative and quantitative differences between time periods. The emphasis is on the content of the phases and the internal dynamics that bring about changes. An example of this is Kübler-Ross' grief model. Related to this are career models as proposed much earlier by Becker (1953), for example.

Cyclical Time: Fourth, another way of looking at temporal orders is circularity, as opposed to the models above, which assume linearity. Circularity implies that changes come back to the beginning: day and night rhythms are an example of this, as are seasons, or the life cycle.

Uncertain Time is the last mode of temporality we want to propose. In this mode, change is a deviation from a known to a less well-known situation including indeterminacy, reflexivity, and doubt, and hence a stronger focus on the present and a less clear, vague or ambiguous attitude towards the unknown future.

\section{Method}

This article is based on a longitudinal ethnographic panel study (see for a similar approach Wöhrer et al., 2020) among first-time parents in Amsterdam, the Netherlands. This panel started in 2016/2017 and, after repeated recruitment and attrition, 21 families were participating at the start of the research. While the sudden emergence of COVID-19 triggered renewed reflection on rapid research methods (Vindrola-Padros et al., 2020), our existing panel study enabled us to start researching COVID-19 policy impacts more or less right away. We did redesign our item list and foregrounded COVID-19related items. We also hired three experienced students to assist in and speed up data collection and analysis (listed as co-authors).

\section{The Sarphati Ethnography Panel}

In our panel, pre-COVID interviews and occasional online chats were triangulated with participant observations at the family home to document and understand the development of health practices in everyday lives in diverse social contexts (Hammersley \& Atkinson, 2007). Using a longitudinal approach, we aim to examine experiences, practices, and competences as they unfold and 
stabilize over time in response to life changes. The panel allowed us to immediately start assessing social distancing and home isolation measures once these were imposed in March 2020. We included parents of different genders, ages, and educational levels in our panel, as well as those with international migration histories.

The panel study has received formal ethical approval from the Ethics Board of our University (AISSR Approval number 20170216999). Participants were recruited by means of a one-page information leaflet and, prior to the first interview, they received extensive additional information about the longitudinal character of the study, their anonymity, and the ability to end their participation when they wished, after which informed consent was provided.

\section{COVID-I 9 Research Participants}

Out of the 21 families in the panel, we engaged 17 families in the analysis for the COVID-19 study on which this article is based. The other four families were not available for research in this period or left the panel. Due to the isolation measures, we switched to telephone interviews and paused observations. We conducted a total of 41 online interviews in the period between March 18 and June 10, 2020 (on face-to-face versus online interviews, see Davies et al., 2020). In addition, we contacted families via email or WhatsApp to set appointments and briefly ask how they were doing. Answers to these questions were used as a prompt for the interviews. While we normally approach families about three times a year, we now approached them once a month on average, to be able to keep track of potential changes in response to changing policy measures and public debates. The extra effort was partly funded by a grant from the Dutch Research Council, NWO (Impact of Social Isolation on Vulnerable Populations during COVID-19 consortium: https://www.coronatijden.nl/).

We spoke to the mothers and in two families also to the fathers, guided by a list of items specific to the COVID-19 period and based on our prior knowledge of the families. We are aware that mothers' reports might not represent all family members' views and made extra efforts to recruit fathers. Our limited success in doing so is in line with the Dutch context, where mothers often spend more time on caring tasks than fathers (Lewis et al., 2008), as well as with a strengthening of gendered caring responsibilities during home isolation, even among egalitarian couples (see Hjálmsdóttir \& Bjarnadóttir, 2020). The semi-structured COVID-19 item list covered the health status of the families, effects of home isolation on household life in general, work, care and health practices, uptake of and toward national prevention measures, and COVID-19-related concerns,
Two thirds of the family members have a university degree or have completed higher vocational training, with one third having vocational or limited educational training. In five of these 17 families, one or more parents are first-generation immigrants (from Denmark, Germany, Japan, the United States, or Russia) or second-generation immigrants from Turkey or Morocco. The parents in 15 of the families comprise a cohabiting heterosexual couple with one or two children. One couple is in the process of getting divorced and is therefore no longer living together. One couple comprises two mothers. Eight of the families have two children and nine of the families have one child. The names of the family members are fictitious. The families all received a gift voucher and a copy of the final report to thank them for participating.

\section{COVID-1 9 Data Collection and Analysis}

At the start of the research, we switched from recording and transcribing interviews to extensive and verbatim note-taking since we expected to conduct short interviews and wanted to be able to assess the data soon. A necessary part of this practice was to refine the notes and turn them into a digital record directly after the interview. After the first couple of note-taking interviews, we evaluated this approach and found that extensive note-taking and immediate elaboration was not only possible but also offered advantages. Using a headset and handwriting notes pushed us to listen closely and focus on answers than on our own questions. Directly working out the notes into a document also enhanced reflection and analysis. The team gathered frequently to exchange and document these reflections and interpretations. Being confined to the home and using online communication repeatedly, coupled to our existing rapport with the families, made it easy to directly talk about crucial issues. In fact, coming from a tradition of face-to-face fieldwork, we were surprised by the relevance and richness of the data even though we could not "be there" temporarily. However, we also found that after the first lock-down, interviews tended to become longer. Therefore, we switched back to recording and transcribing interviews in most cases after this particular research period. With the second lock-down starting at the end of 2020, we are using the short-interview notetaking approach again. In sum, we have learned to appraise and use different approaches flexibly and if necessary rapidly (for a reflection on rapid responses, see Vindrola-Padros et al., 2020).

The sample size is suitable for our interest in "theoretical generalization" (Meyer \& Lunnay, 2013), by showing contextualized accounts of how new parents and particularly mothers develop specific kinds of emotion work and health practices. 


\begin{tabular}{|c|c|c|c|}
\hline & Danger & $\rightarrow$ & Uncertainty \\
\hline Policies & \multicolumn{3}{|c|}{ Lockdown March $2020 \rightarrow$ End lockdown April $\rightarrow$ Easing restrictions June 2020} \\
\hline Temporality & \multicolumn{3}{|c|}{$\begin{array}{l}\text { Interruption } \rightarrow \text { Stand-still (cyclical) } \\
\qquad \begin{array}{l}\text { Phasic and Continuous Change } \\
\text { Increasing Uncertainty about Temporality }\end{array}\end{array}$} \\
\hline $\begin{array}{l}\text { Risk } \\
\text { management }\end{array}$ & Adherence to rules & $\rightarrow$ & Pragmatic Considerations \\
\hline $\begin{array}{l}\text { Emotion } \\
\text { management }\end{array}$ & Solidarity & $\rightarrow$ & Fragmentation \\
\hline
\end{tabular}

Figure I. Conceptual dimensions.

The team of six researchers gathered data separately and analyzed data collectively through abductive thematic analysis (Hsieh \& Shannon, 2005; Timmermans \& Tavory, 2012) in a longitudinal perspective (see above on temporality and Thomson, 2007, for a longitudinal analysis of case histories). ATLAS.ti project bundles were used to apply and share codings and exchange extended memos. For several weeks, team members had almost daily exchanges, which were documented in memos. The material was coded deductively (using practices, risk, emotion management, resonance, and temporality as heuristics) and inductively in parallel. All the team members identified and shared pertinent observations and interpretations. To arrive at interpretations inductively, team members applied longitudinal and cross-sectional analysis as much as analysis by household and by theme. Each interview and all codings were read, shared, and crossvalidated by multiple researchers.

Using a shared Atlas-ti project bundle as the basis, emerging interpretations were continuously grounded in the data and in group-based reflexivity (Barry et al., 1999). The "interpretive zone" (Wasser \& Bresler, 1996) thus created was first condensed by the lead authors into two reports, after the third and sixth month (in Dutch). The reports served as a hypothesis about potential themes (Report 1) and change over time (Report 2) and received extensive feedback from within and outside the team.

\section{Findings: Four Key Themes Developing Over Time}

We have identified four key themes and their development over time in the context of evolving COVID-19 prevention policies (see Figure 1): (a) the lockdown interrupted life and changed experiences of temporality. (b) Following the lockdown, risk management changed from fear to insecurities and (c) simultaneously, emotion management rules transitioned from solidarity to fragmentation. (d) Increasingly, pragmatic considerations allowed parents to tackle uncertainties and created room to normalize everyday life beyond the context of less strict policies. In sum, we interpret this as a shift from danger to uncertainty.

\section{Interruptions in Childcare, Work, and Family Life}

In all families, we noted an interruption of everyday life in the sense that childcare, health, and work were affected by policy restrictions. At the beginning of the lockdown in mid-March 2020, we found that many families in our sample had to reconfigure childcare and work arrangements and thus the work-life balance in their everyday lives. This was not always easy. The childcare situation changed in 12 of the 17 families. Children who had previously gone to day care or to grandparents were cared for by their parents at home. One family engaged a babysitter to come to their house. Out of the six families who were still entitled to childcare due to one or both parents being designated as "key workers" according to national COVID-19 policy, three actually made use of it. In one case, the grandmother continued to babysit even though contact with older people was explicitly discouraged.

Hence, this break in everyday life can be characterized as a "biographical disruption" (Bury, 1982), in which a new reality came to the fore that changed families' experiences of routine and their awareness of time. Many of the parents felt they were locked up and consistently expressed a strong need for time alone, sport, and contacts outside the family.

I adore my kids, but being with them $24 / 7$ is driving me crazy (April).

The need for "me time" and for family members to function somewhat "independently" within the family, enabling parents to step back from their children, was important in a number of these families even before COVID-19 struck (Veltkamp et al., 2020). However, the balance between attachment and detachment was 
disrupted during the lockdown: Parents could not go to the gym or go out with friends, childcare was largely unavailable, and work often had to be done with young children close by. We thus found that time during the lockdown was predominantly experienced as "interrupted" by the COVID-19 event and felt "circular" after the interruption: as if time was standing still and every day was similar.

In an interview after the first lockdown, one mother sighed, "We're much better now" (June). She explained how she now had much more "breathing space" and saw many more opportunities for her and her wife to cope with the still present social distancing measures and health risks. Earlier, she felt locked up, desperately craved time away from her family, and could understand how domestic violence could be an impending threat during lockdown. When her elder daughter (4 years) was able to return to school, the tension slowly decreased in her case, and in many of our other families. Nonetheless, the families still did not feel that life was "normal" and insecurity remained. By the beginning of June 2020, it was rather as though they were living, but with reservations, partly due to the remaining social distancing measures and, more importantly, because of growing uncertainties. Looking at the feelings above in more detail, we see how changes in feelings were being fed by the changing policy on COVID-19. Moreover, we found different phases of change in our respondents' accounts which closely reflected the varying policy regulations. After the partial reopening of schools and nurseries in the Netherlands on May 11, 2020, childcare arrangements changed once more. Children in at least six of the 17 families who initially stayed at home returned to elementary school or day care. Two families kept their children at home and looked after their children themselves. The childcare situation in four families remained unchanged the entire time.

All the parents in the panel had paid jobs during the research period, but the work situation in almost all families changed. At the beginning of the research period, 11 of the 17 families stopped going to their places of work and had to arrange ways of working from home. Sometimes they worked less or their work was halted temporarily. Most families' incomes remained stable, although some were worried that this could change in the future or near future. It is possible that the families who took part in this round of the research are a fortunate section of the population and that families who were already coping with unemployment were less inclined to take part in the research. However, the Dutch government's support policy initially prevented mass unemployment. As time went on, parents in six families returned to their place of work. In almost all cases, this meant a greater number of working hours than at the beginning of the crisis.
All the families said at the start that they were in good health. No one in the families has been diagnosed as having COVID-19, although three families suspect that one of the parents or the child has had the virus. Hence, our study did not point to interruptions in respondents' biographies in relation to having the COVID-19 virus. A few families, however, underwent traumatic personal circumstances during the research period. The mother's father in one family died, as did the mother's grandfather in another family. In addition, one couple is getting divorced. On a happier note: two mothers turned pregnant.

\section{Risk Management: Phasic Shift From Fear to Insecurities}

The first weeks of restrictions in March and April were characterized by fear of infection. As one mother said, "We are still healthy; well, at least for now" (April).

The announcement and implementation of the easing of restrictions led to a shift in risk management from fear of the virus to insecurities about the restrictions. Once the common threat of the virus was seemingly under control, the easing of restrictions opened up space for different perspectives and emotions - and hence insecurity - about the restrictive measures. Parents talked about their insecurities around the reopening of schools and nurseries, and some of the parents kept their children at home for longer than necessary.

\footnotetext{
Yes, I have rather mixed feelings about it [the easing of restrictions]. Obviously, things are as they are at the moment. There aren't as many infections and fewer people are being taken to hospital. I can go to the hairdresser and my beautician again - and I need to. We can stay 1.5 meters apart, but my eyebrows can't. But then again, my son isn't back at school yet, pre-school. I haven't sent him; I said that the last time too. I don't want my son to be some kind of guinea pig. I'm going to wait and see what happens in the next three or four weeks; if things stabilize a bit and if there are hardly any more infections at schools, I might be prepared to send him after all. But not now. No one in my family has sent their children to school (May).
}

Here we can see multiple lines of argumentation and struggles, which are characteristic of reflexivity in a "risk society" (Beck et al., 1994): This mother was scrupulously monitoring developments around COVID-19 and explicitly connected her own "mixed" emotions to them. She used scientific knowledge (number of infections and hospital admissions) and was aware of scientific logic and used it as critique: She did not want her child to be used as a "guinea pig." Scientific knowledge therefore has two functions here: It forms a basis for certainty (infections are decreasing) and a basis for uncertainty (the risk of infection at school). She resolved this tension somewhat by 
monitoring how the situation was progressing, thereby claiming some sort of professional knowledge. She also referred to members of her extended family and, by implication, to experiential knowledge. She also managed the risk of infection by distinguishing between exposing herself and her son, whom she did not wish to expose.

The knowledge parents made relevant in the interviews almost literally resemble the public discourse on scientific findings. Below, a mother contextualized her decision saying,

Especially because it's now been demonstrated that it can spread through the air and that the 1.5 meters is therefore really important (April).

We also found a shift in the way in which parents of young children experienced time in relation to the reservations they described. In the first few weeks of the lockdown, time almost seemed to stand still or, in other words, parents experienced circular time. Every day was like all the others and days became repetitive. Gradually, the parents began to focus more on the outside world. One " "hoped" for more freedom of movement, while another "was worried" about the long-term social and economic consequences of the COVID-19 restrictions. As restrictions began to be eased in May, uncertainty about the future came to the fore. Parents were cautious, wanting to see what would happen, apprehensive, or curious. Once the families found themselves out of the lockdown, which they had so longed for, the future still proved to be uncertain in a different way:

In that sense, I have a wait-and-see attitude and I want to see how things develop in terms of infections over the next few weeks. If I see that there isn't a huge number of new infections, then I'll feel a bit more confident. And then I can start being more relaxed and invite more people over (May).

We see that the respondent had a hesitant attitude and was watching developments, using open descriptions: "isn't a huge number" and "a bit more confident" and "more relaxed." She seemed to be unable to set firm boundaries or make more precise assessments, which we interpret as temporality characterized by uncertainty about knowledge and more fundamentally about changes over time.

Uncertainty oftentimes was literally established with references to precise policy decisions, for example, regarding face masks:

We have to wear face masks on public transport from June 1. It's pretty annoying that you have to arrange to get them yourself. It's not entirely clear whether they actually provide adequate protection. In other countries, supermarkets are handing them out, for example. But here they say, sort it out for yourself. But you have to comply, or otherwise you can be fined 95 euros (May).

The mention of the date is a clear reference to the policy discourse, and the interview also reflected the public debate on the usefulness of face masks. The same happened in other interviews. Some parents were critical about the use of non-medical face masks and seemed to reject their use, but that critical stance perfectly matched the public debate originating in April, for example, when populist leaders were "demanding truth" about the shortage of face masks (NOS, 2020).

While uncertainty was often related to contradictory knowledge, it also pertained to other people's behaviors post-lockdown:

Things are going well, but no one is sticking to the rules. Staying 1.5 meters apart isn't working. Colleagues just come right up to your desk. I don't actually mind, because no one is ill. But it was to be expected (June).

The first sentence describes the situation immediately after the lockdown as both good and threatening. She was in doubt and weighed the situation, which is also expressed in the "but" in the last sentence. She observed how colleagues came closer than 1.5 meters and tried to make sense of that. While this violated the social distancing norm, she also placed it into perspective in two ways: in terms of numbers of infections and in terms of her own expectations.

\section{Emotion Management in Feeling and Framing Rules: From Solidarity to Fragmentation}

Our data show that almost all the parents managed their emotions in relation to the COVID-19 regulations. In the first weeks after the lockdown, they did so particularly with reference to the general frame of the COVID regulations, which called upon solidarity with vulnerable populations and health workers. In the first weeks, parents said that things were going fairly well, and nobody mentioned major problems. They also tended to put their self-evaluations into perspective, saying, "we can't complain."

We can't complain but it's certainly challenging. You get no rest, but we're just glad we're able to work from home (April).

But that [fewer contacts, lots of extra work] is true for everyone. We can't complain, we're doing well, and we should feel compassion for the nurses and doctors (April).

I'm pragmatic, because I can see that things could be worse (March). 
Notice how often "we" was used above, referring to the household and maybe to a generalized other or "everyone." We interpret "can't complain" and similar utterances of the first weeks in lockdown, as "feeling rules" to overcome discrepancies between parents' emotions and their situation (Hochschild, 1979). They contextualized their own situation in two ways: by emphasizing that others in a comparable situation were going through the same (horizontal social comparison) or by comparing their own burden with what they saw as greater problems other people were facing, such as patients, health care workers, the self-employed, the homeless, or people in the cultural sector (downward social comparison/positive relative deprivation). Even parents who cited personal problems made these comparisons. For example, a mother whose husband had left her and was at risk of losing her job said, "It's a huge puzzle for everyone and a worry for us all." Again, a norm and a generalized other were implied through using the frame of "everyone." This can be seen as "framing rules" (Hochschild, 1979), with parents focusing on circumstances others are in. The following excerpt shows the contexts parents make relevant: people in poor health, self-employed, homeless people.

Obviously mother, too, would love to work more, see her father again, go out to dinner, but compared to people in poor health or all those self-employed people (. . .) "in a lot of ways I feel: don't whine, pull yourself together." (April)

The respondent was worried about "society," not about herself, and she mentioned homelessness, poverty, domestic violence, and child abuse; social issues which had all been on the news in previous evenings.

The phrase "don't whine" is almost literally a feeling rule or at least very generalizing. Mother also seemed to suggest that she had to remind herself of this norm given her desire to "work more, see her father again," and so on. ${ }^{1}$

Hence, in the first few weeks, in line with the construction of COVID-19 as a collective risk, parents framed their own situation and those of friends or family on the basis of solidarity and reasoned that everybody had to adapt to prevent the spread of COVID-19 among vulnerable groups and avoid overwhelming the health services and health care workers. The risk was thus allocated to others and parents tried to adjust their emotions to fit that frame of solidarity (for a similar observation about the power of solidarity frames for emotion work, see Grootegoed et al., 2013).

Emotion management changed toward the end of April: We heard more criticism, more complaints, and discontent about - and due to - the altered context of emotion management. Once the collective risk of COVID-19 became less pressing and urgent, solidarity was replaced by reflexivity, uncertainty, and fragmentation.
To start with, we observed fewer references to the problems suffered by vulnerable older people and the burden on the health care system from mid-April on. Instead, mothers and fathers talked more about other people who were not sticking to the rules, parents were "fed up" and complained that isolation had lasted too long. They felt that it had been too long since they had been able to visit their own parents, that it was tough not to be together as a family for Ramadan, or that it was unclear when face masks were or were not needed. The frame of solidarity crumbled: Parents emphasized their own problems and justified their anger or doubts. Parents argued for more freedom or more enforcement and clearer rules. Some tended to be even stricter than necessary according to the letter of the law:

They announce a tiny easing of restrictions and the whole street fills up again . . . people just don't listen, they'll have to be much stricter (May)

Above we saw that a collective frame was constructed through the use of "we" and "everyone" and through mentioning other people's suffering. In the last fragment, the mother constructed at least two general actors: "they," which seems to refer to the government, and "people" as breaking the rules. Instead of a "we," she felt confronted with two "theys." She still, however, assumed that the rules were correct and ought to be adhered to; that justified her anger. At the same time, she was also bewildered about the restrictions imposed on her grandmother in the care home, expressed in the following excerpt.

\footnotetext{
"My mother has had enough of it all and my grandma doesn't understand it; she's 94 and I have to tell her again and again that I can't come close to her." Naomi had to wear a face mask when she went to visit her grandmother and was only able to look at her through the window. "It was raining and my grandma tried to open the door because she felt sorry for me standing in the rain. . . . It was tragic. . . . That's really going too far: a face mask when you're just looking through the window." And after the death of someone she knew, she said: "No one should die alone. That's just wrong" (May).
}

We interpret this as fragmentation: Besides solidarity, which supports emotional self-restraint, we found a legalistic frame and a personal liberty frame justifying indignation, anger, sadness, and regret. By May, citizens had become a risk to each other, individual risks were stressed, and emotions were less restrained. This different phase, which came with different fears, also entailed a different experience of time. At the beginning of the lockdown, parents waited for the easing of the restrictions and risk mitigation. Later on, they worried more about their current situation. In this way, COVID-19related risks changed and arrived in the present, while expectations of the future became more unclear. The 
following paragraph will bring to the fore how changing COVID-19 restrictions played out in people's day-to-day self-regulation.

\section{Increasing Uncertainty and Pragmatic Interpretations}

We thus observed that managing emotion took different paths after the easing of restrictions. In a similar manner, families' risk management also diversified. All the families said that they adhered to the rules on social distancing and hygiene in the period from the end of March to the end of April. At the same time, they made all kinds of exceptions from day one, and the easing of restrictions, once started, had a powerful self-propelling effect. Parents applied the logic of the easing of restrictions to more and more situations. In the words of one of those interviewed: "we're easing off" (May).

We observed from the beginning that parents stretched the rules and modified risk assessments to accommodate the things they considered important in their family. In the case of visiting grandparents, for example, visits were sometimes judged to be possible, even in the first few weeks, because grandma was still "fit" and therefore the risk was assumed to be lower. A low risk could therefore have different ramifications in a pragmatic context. What were these pragmatic circumstances in which families accepted risks of infection? The most moving is perhaps the story of a grandmother whose husband had recently been violently killed. In that situation, the family wanted to support the grandmother by visiting her regularly. In another family, the pragmatic assessment involved the child. The mother still met up with her friend who also has a young child. This friend, she said, is also very careful about her social contacts and "Children are desperate to play with other children; it's difficult to say no" (April). She also said that her son is really struggling with everything that has had to stop due to the isolation. And so, the mother said, they still visit the grandparents. In other cases, a mother herself was in need of contact, as we see in the case below.

"What I really miss . . . I love touching, I miss it dreadfully. Being able to hug someone, put a hand on their shoulder." And, to be honest, she recently did touch her friends after having a few drinks. But "it's still not the same." (April).

Parents occasionally went grocery shopping together, instead of alone as recommended, because they had not seen each other all day and they wanted to spend some time together. And when one mother's friend needed a cuddle, she did give her a hug; in other words, as they said themselves "we're following the rules strictly, with some exceptions."
Parents made room for contact outside the family when they themselves or others felt lonely or when there were other reasons to do so. They then drew new boundaries. The description below shows how attention was divided between the divorced grandparents and how little distance was kept during visits. This was mentioned in the context of "visiting family once or twice" and "apart from that, not too many" contacts outside the home.

We did visit family members once, but otherwise we haven't been outside very often. . . . We went to visit my mother and my father; they're divorced so that was two different places. We carried on as usual, because you've got the children going from one to the other, and none of us had any health issues. We had contact with each other as we normally do. We didn't keep a distance from each other (May).

Parents used the uncertainty in risk knowledge and the changing scope offered by the Dutch COVID-19 policy to interpret the social distancing rules to better suit their lives. In terms of temporality, the changing construction of risk and feeling rules enabled more room to maneuver and enabled parents to foreground immediate needs above future consequences.

Parents also saw other people's behavior as a context within which they could put their own interpretation on the social distancing rules.

I do still try to keep my distance from everyone and everything as much as I can. I went into the center of town for a little while and I noticed that it was really crowded in some places, because only a limited number of people are allowed into shops at one time. People squeeze past each other and are less likely to wait. People also feel a bit less inhibited, and the weather helps; it always makes people happier and then they forget the rules. I have to be honest . . . Because we're having painting work done, I had to go to Almere, where my mother lives, so that's where we are now too. That's the only thing, because it's not as though I said to myself let's go to a bar for a drink; I'm not doing that yet (June).

This mother evaluated her own breach of the rules in relation to what she saw happening all around her and, at the same time, made it clear that she had not abandoned all restraints. She was looking for a balance in her own interpretation of the COVID-19 restrictions.

The "other people" which parents are referencing are not only those observed directly. Parents often refer to media coverage, using words and themes and reproducing the tensions reported in media, for example, concerning breaking the rules:

Remember the first week that happened? That weekend . . . All those idiots who trooped to the Amsterdam Forest to look at the cherry blossom? That was us! We hadn't given it a thought. It was an eye-opener though (April). 
Learning about policy restrictions in personal and media contexts and applying rules to their own lives, over a period of only 10 weeks, parents developed new and, at that moment, seemingly sustainable rules. They did so in the pragmatic context of compromising between dangers, restrictions, and expectations about other people's behavior.

So we avoid crowds and we follow the government rules, but we also make our own rules. It needs to be doable. We can't wash our kids' hands every time they touch something at the playground, so we just give them a rice cake. What if we can't find disinfectant wipes or gel at the local drugstore? I don't want to have a mental breakdown about that. So we make our own rules (June).

Parents thus simultaneously took account of the changing policy, public discourse, uncertainties, and the wishes and needs of everyday life. That produced a variety of ways in which mothers and fathers incorporated the rules into their lives, and they no longer wanted to have a "mental breakdown" about every potential risk. Often parents gradually eased their own rules, which triggered even more lax behavior.

In contrast to the tendency to "ease off," some parents were stricter than recommended and kept their children entirely at home for a while. Tightening the household rules was as much a response to changing risk constructions as it was "easing off." By their own account, strict parents wanted to "take no unnecessary risks" (April). The elder daughter in on family would have been allowed to join her mother at day care, but the mother kept her at home:

Despite the fact that some research says that children don't spread it that easily (April).

The choice of words such as "some" and "not so easily" are telling. The uncertainty in risk assessment was the reason for this mother to make a definite decision to keep her child at home. This uncertainty can also be a frame that enables the foregrounding of fear. The mother in another family was unsure about taking her child back to day care after the May holiday:

They say that the infection hardly spreads among children but there's always a chance and that makes me anxious (April).

When we look at the "probability" of spreading the infection, this mother said correctly that there is always a chance of infection. The problem she and all the parents seemed to be struggling with to some degree was how knowledge of risks and statistical probabilities should be translated into concrete decisions. The final section will address this problem in the wider perspective of the overall conclusion of our analysis.

\section{Discussion and Conclusion}

Between the end of March and the beginning of June 2020 , we repeatedly spoke to 17 families with young children, who had already been members of the longitudinal ethnographic panel for several years. From March onward, we talked to them about the way in which they were coping with the COVID-19 restrictions and the threats to their health. We observed that, in just 10 weeks, the way in which the families managed health risks and dealt with COVID-19 in their lifeworld changed markedly in response to changes in restriction policies. The policy reverberated almost literally through their daily lives. People adopted the words and themes of the public and policy discourse and they reproduced and related to the tensions in the public discourse. The deep impact of changing social isolation and distancing measures was obvious in parents who followed the rules as much as it was in parents who deviated from and criticized the rules. Either way, COVID-19 was a prime point of reference in the construction of risk frames and feelings rules. Studying risk perceptions in everyday experiences in the lifeworld thus shows how families used emotions, (dis) trust, and pragmatic considerations to interpret risk aiming to reduce uncertainty (Zinn, 2008) in their response to COVID-19 policies and public discourse. In doing so, perceptions of risk shifted from worries over a negative outcome to a more profound unsettling disruption of taken-for-grantedness (Alaszewski \& Coxon, 2009).

Our research brings various changes to the fore, which we differentiate conceptually using a novel model for temporality (based on Ramanujam et al., 2020). During the 10 weeks we studied, breaks and disruptions, gradual increases/decreases, cycles, phases, and uncertainties about time were visible. After the initial break with normality, we saw that life froze or came to a halt in some ways in the first few weeks. For some, this meant that the days just carried on at home, with much repetition; for others, it meant a severe feeling of constriction. These and other negative emotions were initially managed by conforming to the call for solidarity (Grootegoed et al., 2013) in light of the construction of COVID-19 as a danger. Compared with the problems other people were facing, parents did not want to complain. This form of deep "emotion work" (Hochschild, 1979) changed during April and May. The easing of restrictions gave parents justification for managing their emotions differently. Rather than bringing a sense of calm, the gradual policy change heralded different uncertainties: about the usefulness and necessity of specific measures, about the effect of measures, or about the duration of the crisis. During this 
process, the perspective shifted from danger to risk. The anticipated danger of infection slid into the background and political and private management of the risk of infection itself became a source of uncertainty (Beck et al., 1994). Solidarity began to crumble in this phase (midApril to mid-May) and greater differences appeared in how parents experienced COVID-19 restrictions, how they managed themselves, and how they behaved. Gradually, time became more blurred or uncertain as well.

While uncertainty seemed to be the overarching theme in the second half of the fieldwork, it had different ramifications. In some situations, uncertainty was a frame that justified the feeling rule that one should be alert or anxious and "better safe than sorry." In other instances, uncertainty about COVID-19 risks was a frame that suggested that one can be more relaxed about infections. In both types, uncertainty about the future affected parents' perception of time. Not knowing how long restrictions would last and doubts about effectiveness of policies blurred time horizons (see Alaszewski \& Coxon, 2009). Emotion work in the context of uncertainty thus mingled the present and the future (Brown et al., 2013).

Uncertainty also meant that parents had difficulty translating general rules into everyday decisions. It seems that short-term personal and family needs received more attention than long-term consequences of actions. While this is generally observed in psychological and economic research, our study demonstrates how these balances can rapidly shift under different social conditions. The shift from solidarity to uncertainty triggered different forms of emotion management. Differently modulated feelings in turn enter into everyday risk practices.

It is hard to disentangle how changing everyday "emotion-risk assemblages" relate to temporalities (Lupton, 2013). It seems that the emotion work in the context of specific risk framings at least favors certain temporalities. COVID-19 in the frame of an immediate danger and solidarity-based responses might lead to the experience of a break followed by a standstill. Gradually rising uncertainty coupled with situation-specific and fragmented emotion management strategies, engenders the experience of phasic shift and confusing time horizons. Our study contributes to ethnographic and longitudinal research and studies about health and social policies by distinguishing and disentangling temporalities and their relations to emotion and risk work, thereby conceptualizing change over time in everyday lives. While we have applied this framework to the highly relevant intersection of risk and time (Brown et al., 2013), we suggest that it has wider applicability.

We had expected budding family life to be a vulnerable period. After all, that is exactly the time when children, work, and housing arrangements are developing in a context of high hopes about "intensive parenting" and "risk management" (Grunow \& Veltkamp, 2016; Lee et al., 2010; Veltkamp et al., 2020). Indeed, our data show the high caring demand and "intensive mothering" (Hays, 1996) in particular during home isolation (see also Swan, 2020), next to experiences of stronger bonding and intimacy (see also Evans et al., 2020). As far as we can tell, the families we studied are - subject to reservations and with some limitations - starting to pick up their lives once more. This is partly because parents are continually trying to adapt general measures to their own situation. Not infrequently, this means that they establish contacts, which, from a public health point of view, seem unwise. At the same time, our analysis shows that parents have good reasons for doing so, and as such, seem to be protecting their own health and that of their loved ones in the sense of their well-being. Our research can therefore be useful to policy makers and practitioners to provide a better understanding of families' health behaviors and responses to policies in times of health crises.

We used an ethnographic design with a sample size suitable for "theoretical generalization" (Meyer \& Lunnay, 2013) to show contextualized accounts of new parents' emotion work and health practices. A limitation of our study is that our respondents were mainly mothers and that none of our respondents faced severe health or financial constraints due to the COVID-19 pandemic and policies, which is reflected in our results. Moreover, we focused on the first 10 weeks since the spreading of the virus in the Netherlands and used methods that provided less in-depth data. As a consequence, we missed out on investigating more general dimensions of parenting and social life. At the same time, this enabled us to connect with families more frequently and flexibly and thus capture health and risk practices and emotions that developed over time, which was valuable for "rapid qualitative research" during a pandemic. Since we used an ongoing ethnographic study, we did not face strong barriers to achieve ethical clearance in time (Vindrola-Padros et al., 2020).

In sum, it seems evident that the COVID-19 policy and the construction of risk deeply and dynamically impinged on people's health care practices and experiences and that this happened in different ways, gradually moving from acceptance and solidarity to increasing debate and fragmentation. This fragmentation then entered into policy measures to which citizens reacted anew in the Netherlands and many other countries.

\section{Acknowledgments}

We are grateful to the parents for their time and sharing their experiences during COVID-19 regulations, and to their children for being patient during the data collection activities. We are grateful as well to Franca de Waard and the midwives for their assistance with the recruitment of participants, and to Gerben Moerman for contributing to the research design. We thank the 
anonymous reviewers for their valuable comments on earlier versions of this article.

\section{Declaration of Conflicting Interests}

The authors declared no potential conflicts of interest with respect to the research, authorship, and/or publication of this article.

\section{Funding}

The authors disclosed receipt of the following financial support for the research, authorship, and/or publication of this article: This research was funded by the Municipal Health Service Amsterdam, the Urban Mental Health research priority area of the University of Amsterdam (UMH), and by the Dutch funding agency for health research ZonMw as part of the SocialIsolation consortium. The panel as a whole is embedded in the epidemiological cohort study Sarphati Amsterdam.

\section{ORCID iD}

Christian Bröer (iD https://orcid.org/0000-0002-6381-0233

\section{Note}

1. Based on suggestions by Patrick R. Brown, University of Amsterdam.

\section{References}

Alaszewski, A., \& Coxon, K. (2009). Uncertainty in everyday life: Risk, worry and trust. Health, Risk \& Society, 11(3), 201-207.

Barry, C. A., Britten, N., Barber, N., Bradley, C., \& Stevenson, F. (1999). Using reflexivity to optimize teamwork in qualitative research. Qualitative Health Research, 9(1), 26-44. https://doi.org/10.1177/104973299129121677

Beck, U., Giddens, A., \& Lash, S. (1994). Reflexive modernization: Politics, tradition and aesthetics in the modern social order. Stanford University Press.

Becker, H. S. (1953). Becoming a marihuana user. American Journal of Sociology, 59(3), 235-242. https://doi.org $/ 10.1086 / 221326$

Blue, S., Shove, E., Carmona, C., \& Kelly, M. P. (2016). Theories of practice and public health: Understanding (un) healthy practices. Critical Public Health, 26(1), 36-50. https://doi.org/10.1080/09581596.2014.980396

Bröer, C. (2006). Beleid vormt overlast. Uitgeverij Aksant, Amsterdam.

Brown, P. (2020). Studying COVID-19 in light of critical approaches to risk and uncertainty: Research pathways, conceptual tools, and some magic from Mary Douglas. Health, Risk \& Society, 22(1), 1-14. https://doi.org/10.10 80/13698575.2020.1745508

Brown, P., \& de Graaf, S. (2013). Considering a future which may not exist: The construction of time and expectations amidst advanced-stage cancer. Health, Risk \& Society, 15(6-7), 543-560. https://doi.org/10.1080/13698575.2013 .830081

Brown, P., Heyman, B., \& Alaszewski, A. (2013). Timeframing and health risks. Health, Risk \& Society, 15(6-7), 479-488. https://doi.org/10.1080/13698575.2013.846303
Bury, M. (1982). Chronic illness as biographical disruption. Sociology of Health \& Illness, 4(2), 167-182. https://doi. org/10.1111/1467-9566.ep11339939

Chasson, M., \& Taubman-Ben-Ari, O. (2020). Early maternal caregiving: A conceptualization of maternal compassion preoccupation. Qualitative Health Research, 30(9), 1303 1313. https://doi.org/10.1177/1049732320908570

Cohen, M. H. (1995). The triggers of heightened parental uncertainty in chronic, life-threatening childhood illness. Qualitative Health Research, 5(1), 63-77. https://doi.org $/ 10.1177 / 104973239500500105$

Davies, L., LeClair, K. L., Bagley, P., Blunt, H., Hinton, L., Ryan, S., \& Ziebland, S. (2020). Face-to-face compared with online collected accounts of health and illness experiences: A scoping review. Qualitative Health Research, 30(13), 2092-2102. https://doi.org/10.1177/1049732320935835

de Graaff, M. B. (Bert), \& Bröer, C. (2019). Governance and risk in everyday life: Depoliticization and citizens' experiences of cell site deployment in the Netherlands and Southern California. Journal of Risk Research, 22(12), 1586-1601. https://doi.org/10.1080/13669877.2018.1501596

Emirbayer, M., \& Mische, A. (1998). What is agency? American Journal of Sociology, 103(4), 962-1023. https:// doi.org/10.1086/231294

Evans, S., Mikocka-Walus, A., Klas, A., Olive, L., Sciberras, E., Karantzas, G., \& Westrupp, E. M. (2020). From 'It has stopped our lives' to 'Spending more time together has strengthened bonds': The varied experiences of Australian families during COVID-19. Frontiers in Psychology, 11, 2906.

Faircloth, C. (2014). Intensive parenting and the expansion of parenting. In Parenting culture studies. Palgrave Macmillan. https://doi.org/10.1057/9781137304612_2

Felt, U., Felder, K., Öhler, T., \& Penkler, M. (2014). Timescapes of obesity: Coming to terms with a complex sociomedical phenomenon. Health, 18(6), 646-664. https://doi. org/10.1177/1363459314530736

Giddens, A. (1991). Modernity and self-identity: Self and society in the late modern age. Stanford University Press.

Grootegoed, E., Bröer, C., \& Duyvendak, J. W. (2013). Too ashamed to complain: Cuts to publicly financed care and clients' waiving of their right to appeal. Social Policy and Society, 12(3), 475-486. https://doi.org/10.1017/ S1474746413000092

Grunow, D., \& Veltkamp, G. (2016). Institutions as reference points for parents-to-be in European societies: A theoretical and analytical framework. In D. Grunow \& M. Evertsson (Eds.), Couples' transitions to parenthood: Analyzing gender and work in Europe (pp. 3-33). Edward Elgar.

Hajer, M. (2003). A frame in the fields: Policy making and the reinvention of politics. In M. Hajer \& H. Wagenaar (Eds.), Deliberative policy analysis: Understanding governance in the network society (pp. 88-110). Cambridge University Press.

Hammersley, M., \& Atkinson, P. (2007). Ethnography: Principles in practice. Routledge.

Hays, S. (1996). The cultural contradictions of motherhood. Yale University Press.

Hjálmsdóttir, A., \& Bjarnadóttir, V. S. (2021). "I have turned into a foreman here at home": Families and work-life 
balance in times of COVID-19 in a gender equality paradise. Gender, Work and Organization, 28(1), 268-283.

Hochschild, A. R. (1979). Emotion work, feeling rules, and social structure. American Journal of Sociology, 85(3), 551-575. https://doi.org/10.1086/227049

Hsieh, H. F., \& Shannon, S. E. (2005). Three approaches to qualitative content analysis. Qualitative Health Research, 15(9), 1277-1288. https://doi.org/10.1177/10497323052 76687

Jiang, X. (2009). The virtual SARS epidemic in Europe 20022003 and its effects on European Chinese. Health, Risk \& Society, 11(3), 241-256. https://doi.org/10.1080/136985 70902887498

Kamin, T., Perger, N., Debevec, L., \& Tivadar, B. (2020). Alone in a time of pandemic: Solo-living women coping with physical isolation. Qualitative Health Research, 31(2), 203-217. https://doi.org/10.1177/1049732320971603

Knaak, S. J. (2010). Contextualising risk, constructing choice: Breastfeeding and good mothering in risk society. Health, Risk \& Society, 12(4), 345-355. https://doi.org /10.1080/13698571003789666

Lee, E., Macvarish, J., \& Bristow, J. (2010). Risk, health and parenting culture. Health, Risk \& Society, 12(4), 293-300. https://doi.org/10.1080/13698571003789732

Lewis, J., Knijn, T., Martin, C., \& Ostner, I. (2008). Patterns of development in work/family reconciliation policies for parents in France, Germany, the Netherlands, and the UK in the 2000s. Social Politics, 15(3), 261-286. https://doi. org/10.1093/sp/jxn016

Lupton, D. (2006). Sociology and risk. In G. Mythen \& S. Walklate (Eds.), Beyond the risk society: Critical reflections on risk and human security (pp. 11-24). Open University Press.

Lupton, D. (2013). Risk and emotion: Towards an alternative theoretical perspective. Health, Risk \& Society, 15(8), 634-647.

Matthewman, S., \& Huppatz, K. (2020). A sociology of Covid19. Journal of Sociology, 56(4), 675-683. https://doi. org/10.1177/1440783320939416

Meyer, S. B., \& Lunnay, B. (2013). The application of abductive and retroductive inference for the design and analysis of theory-driven sociological research. Sociological Research Online, 18(1), 86-96. https://doi.org/10.5153/sro.2819

Miao, M., Dahm, M. R., Li, J., Thomas, J., \& Georgiou, A. (2020). Managing uncertainty during the communication of diagnostic test information between patients and clinicians in Australian emergency care. Qualitative Health Research, 30, 1287-1300. https://doi.org/10.1177/1049732320913037

Möhring, K., Naumann, E., Reifenscheid, M., Wenz, A., Rettig, T., Krieger, U., Friedel, S., Finkel, M., Cornesse, C., \& Blom, A. G. (2021). The COVID-19 pandemic and subjective well-being: Longitudinal evidence on satisfaction with work and family. European Societies, 23, S601-S617. https://doi.org/10.1080/14616696.2020.1833066

Neale, B. (2015). Time and the lifecourse: Perspectives from qualitative longitudinal research. Researching the Lifecourse: Critical Reflections from the Social Sciences, 25-42.

NOS/Dutch Broadcasting Foundation. (2020, April 16). Tweede Kamer: denk na over gebruik van mondkapjes in openbare ruimte. https://nos.nl/artikel/2330681-tweedekamer-denk-na-over-gebruik-van-mondkapjes-in-openbare-ruimte.html

Parry, C. (2003). Embracing uncertainty: An exploration of the experiences of childhood cancer survivors. Qualitative Health Research, 13(2), 227-246. https://doi.org $/ 10.1177 / 1049732302239600$

Ramanujam, A., Bröer, C., Moerman, G., \& Giani, S. (2020). Temporality in qualitative longitudinal studies on health experience: A review and analysis. In E. Schilling \& M. O'Neill (Eds.), Frontiers in time research (pp. 495-518). Springer.

Swan, E. (2020). COVID-19 foodwork, race, gender, class and food justice: An intersectional feminist analysis. Gender in Management. https://doi.org/10.1108/GM-08-2020-0257

Thomson, R. (2007). The qualitative longitudinal case history: Practical, methodological and ethical reflections. Social Policy and Society, 6(4), 571-582. https://doi.org/10.1017/ s1474746407003909

Timmermans, S., \& Tavory, I. (2012). Theory construction in qualitative research. Sociological Theory, 30(3), 167-186. https://doi.org/10.1177/0735275112457914

Veltkamp, G., Karasaki, M., \& Bröer, C. (2020). Family health competence: Attachment, detachment and health practices in the early years of parenthood. Social Science \& Medicine, 266, 113351. https://doi.org/10.1016/j.socscimed .2020 .113351

Vindrola-Padros, C., Chisnall, G., Cooper, S., Dowrick, A., Djellouli, N., Symmons, S. M., Martin, S., Singleton, G., Vanderslott, S., Vera, N., \& Johnson, G. A. (2020). Carrying out rapid qualitative research during a pandemic: Emerging lessons from COVID-19. Qualitative Health Research, 30(14), 2192-2204. https://doi.org/10.1177/1049 732320951526

Wasser, J. D., \& Bresler, L. (1996). Working in the interpretive zone: Conceptualizing collaboration in qualitative research teams. Educational Researcher, 25(5), 5-15. https://doi. org/10.3102/0013189X025005005

Wöhrer, M. D. V., Jesser, M. D. A., Mataloni, B., \& Schmidt, A. (2020). Insights from setting up the first wave of a qualitative longitudinal study. International Journal of Qualitative Methods, 19. https://doi.org/10.1177/1609406920954057

Zinn, J. (2008). Heading into the unknown: Everyday strategies for managing risk and uncertainty. Health Risk \& Society, 10(5), 439-450.

\section{Author Biographies}

Christian Bröer is an associate professor of sociology with an interest in the relation between health experiences and institutions and an interest in collaborative, longitudinal and participatory methods.

Gerlieke Veltkamp is postdoctoral researcher with an interest in trust and inequality in care settings and urban contexts.

Carolien Bouw is lecturer in sociology with an interest in urban and neighboorhood lives.

Rein de Sauvage Nolting, Femke Borst and Noa Vlaar are students of sociology with interest in care, inequality and gender. 